\title{
Recoverable acrylamide-vinylamine copolymer immobilized TEMPO mediated oxidation of cellulose with good catalytic performance and low cellulose degradation
}

\section{Tingting Sun}

Hebei University of Science and Technology

Huimin Wang

Hebei University of Science and Technology

Jiaye Liu

Hebei University of Science and Technology

Xiaomeng Chu

Hebei University of Science and Technology

Xuteng Xing

Hebei University of Science and Technology

Shaojie Liu ( $\square$ sjliu16@163.com )

Hebei University of Science \&amp; Technology https://orcid.org/0000-0002-7994-4930

\section{Erjun Tang}

Hebei University of Science and Technology

Xinying Liu

University of South Africa

Diane Hildebrandt

University of South Africa

\section{Research Article}

Keywords: Acrylamide-vinylamine copolymer immobilized TEMPO, Cellulose oxidation, Degradation degree, Catalyst recycling

Posted Date: February 15th, 2021

DOl: https://doi.org/10.21203/rs.3.rs-184085/v1

License: (c) (1) This work is licensed under a Creative Commons Attribution 4.0 International License. Read Full License 
Version of Record: A version of this preprint was published at Cellulose on March 18th, 2021. See the published version at https://doi.org/10.1007/s10570-021-03832-8. 


\section{Abstract}

In this work, a recoverable acrylamide-vinylamine copolymer immobilized TEMPO (P(AM-co-VAm)-T) catalyst for selective oxidation of cellulose with good catalytic performance and low cellulose degradation was developed. Firstly, the acrylamide-vinylamine copolymer (P(AM-co-VAm)) was prepared by Hofmann degradation of polyacrylamide (PAM). Then, the condensation reduction reaction between amine groups of $\mathrm{P}(\mathrm{AM}-\mathrm{co}-\mathrm{VAm})$ and carbonyl groups of 4-oxo-TEMPO yielded $\mathrm{P}(\mathrm{AM}-\mathrm{co}-\mathrm{VAm})$-T. P(AM-coVAm)-T was used as a catalyst for selective oxidation of $\mathrm{C} 6$ primary hydroxyl groups of cellulose to carboxyl groups. The carboxyl content of obtained oxidized cellulose was up to $1.114 \mathrm{mmol} / \mathrm{g}$, which was equivalent to $76 \%$ of the free TEMPO level. This macromolecular catalyst was easily recycled and the recycling performance was excellent. Interestingly, it was found that P(AM-co-VAm)-T could effectively reduce the degradation of oxidized cellulose. The corresponding degradation degree was $21 \%-27 \%$, which was much lower than the degradation degree of free TEMPO (61\%-66\%) and other macromolecular TEMPO catalysts, such as polyacrylic acid immobilized-TEMPO (41\%-53\%) and polyamidoamine supported TEMPO (28\%-44\%). P(AM-co-VAm)-T with positive charge and suitable size could effectively inhibit the formation of $\mathrm{C} 6$ aldehydes and $\mathrm{C} 2 / \mathrm{C} 3$ ketones, which was the main reason that it could significantly inhibit cellulose degradation.

\section{Introduction}

The use of 2,2,6,6-tetramethylpiperidine-N-oxyl (TEMPO) for the oxidation of primary alcohol groups in polysaccharides was firstly reported in 1994 (De Nooy et al. 1994). Since then, the selective oxidation of various polysaccharides, especially cellulose, has been a hot research topic. When native cellulose is oxidized by $\mathrm{TEMPO} / \mathrm{NaBr} / \mathrm{NaClO}$ system at $\mathrm{pH}=10.5$, the $\mathrm{C} 6$ primary hydroxyl groups on the cellulose surface are effectively converted into carboxyl groups to produce the TEMPO oxidized cellulose nanofibers (TOCN) as new bio-based nano-materials (Saito et al. 2004; Fukuzumi et al. 2009). They have high optical transparency, flexibility, high dimensional thermal stability and high oxygen-barrier properties (Saito et al. 2004; Fukuzumi et al. 2009). However, two major drawbacks still exist in the TEMPOmediated oxidation of cellulose process. Firstly, the oxidation causes severe depolymerization of the cellulose backbone (Shibata and Isogai 2003; Saito et al. 2009), leading to oxidized cellulose with poor mechanical properties. Secondly, TEMPO is a toxic reagent for aquatic life (Jun et al. 2019), and cannot be discarded into the wastewater network, which raises concerns regarding its recycling.

In order to overcome the depolymerization issue, several improvements have been made to the original oxidation system. It was reported that $\mathrm{TEMPO} / \mathrm{NaOCl} / \mathrm{NaClO}_{2}$ under weakly acidic $(\mathrm{pH}=3.5-6.8)$ bromidefree catalytic oxidation (Zhao et al. 1999; Saito et al. 2009, 2010; Isogai et al. 2011a; Tanaka et al. 2012), electro- TEMPO-mediated oxidation of cellulose (Isogai et al. 2010, 2011b; Jin et al. 2014), TEMPO/laccase/ $\mathrm{O}_{2}$ in water under neutral conditions (Jiang et al. 2017; Yu et al. 2016; Quintana et al. 2017) and TEMPO/ $\mathrm{Na}_{2} \mathrm{SO}_{4} / \mathrm{NaClO}$ at pH 10 (Yui et al. 2013) can maintain high crystallinity and high degree of polymerization of cellulose. 
Other radical catalytic systems are also used for cellulose oxidation. Isogai et al. (Takaichi and Isogai 2013; Takaichi et al. 2014; Hondo et al. 2019) found that 2-azaadamantane N-oxyl

$(A Z A D O) / \mathrm{NaBr} / \mathrm{NaClO}$ oxidation system needed less time to reach a similar cellulose oxidation degree as the TEMPO system. The crystallinity, crystal structure, and crystal size of cellulose were not changed in all oxidized cellulose products. Moreover, oxidized cellulose post-reduced with $\mathrm{NaBH}_{4}$ showed high carboxylate content and high degree of polymerization. Non-persistent free radicals, such as N-hydroxy3,4,5,6-tetraphenylphthalimide (NHTPPI), N-hydroxybenzotriazole (HBT), violuric acid (VA) and Nhydroxyphthalimide (NHPI), as selective oxidation agents for cellulose, can make the original sample morphology retained and deliver slight depolymerization (Araki et al. 1998; Saito et al. 2005, 2006; Coseri et al. 2009, 2013, 2015, 2018; Melone and Punta 2013; Biliuta et al. 2013; Coseri 2017; Isogai et al. 2018).

Immobilizing TEMPO onto inorganic/organic carriers is an effective way to realize its recycling. However, water-insoluble immobilized TEMPO catalysts are generally ineffective for selective oxidation of cellulose, because cellulose is a water-insoluble polymeric substrate. The recoverable water-soluble macromolecular TEMPO catalysts have been developed for effective oxidation of cellulose. For example, Araki et al (Araki et al. 2016) grafted 4-OH-TEMPO to polyethylene glycol 2000 (mPEG2000) to obtain a water-soluble macromolecular catalyst of mPEG2000-TEMPO for selective catalytic oxidation of cellulose. mPEG2000-TEMPO can be extracted using dichloromethane and reused for further oxidation cycles. However, the catalytic performance decreased sharply after recovery.

Our group also reported several water-soluble macromolecular catalysts, such as: poly (ethylene glycol)-bpoly(2,2,6,6-tetramethylpiperidinyloxy-4-yl-methacrylate) (PEG-PTMA) (Liu et al. 2017); polyacrylic acid immobilized-TEMPO (P(AA-co-TA)) (Liu et al. 2018a); and polyamidoamine (PAMAM) supported TEMPO (PAMAM-TEMPO) (Liu et al. 2018b; Liang et al. 2020). We used these catalysts to obtain C6 carboxyl cellulose (The dosage of $\mathrm{NaClO}$ was $5 \mathrm{mmol} / \mathrm{g}$ cellulose). These macromolecular catalysts can be recycled easily and maintain their high catalytic performances. In addition, it was found that these macromolecular catalysts reduced the degradation of cellulose to some extent (Liu et al. 2018b; Liang et al. 2020), which provided a new way to overcome the degradation issue.

Polyvinylamine (PVAm), as a good water-soluble polymer, have abundant primary amines and can spontaneously adsorb on most surfaces in water, creating a cationic interface (Pelton 2014). The high amine content can improve TEMPO loading and the cationic interface can reduce the steric hindrance when oxidizing cellulose. Pelton et al. (DiFlavio et al. 2007; Pelton et al. 2011; Liu et al. 2013; Shi et al. 2014; Fu et al. 2017; Yang et al. 2019) immobilized TEMPO on PVAm by acylation between amino groups of PVAm and carboxyl groups of 4-COOH-TEMPO to give PVAm-TEMPO. They used PVAmTEMPO/ $\mathrm{NaBr} / \mathrm{NaClO}$ to oxidize the $\mathrm{C} 6$ hydroxyl groups of cellulose to aldehyde groups (The dosage of $\mathrm{NaClO}$ was about $0.4 \mathrm{mmol} / \mathrm{g}$ cellulose) that reacted with the primary amine groups on PVAm to form covalent bonds, which promoted cellulose-to-cellulose wet adhesion. Because PVAm-TEMPO was grafted to the cellulose surface, the recycling of TEMPO could not be realized and the cellulose depolymerization issue was also not involved. As far as we know, the strategy that addresses both recycling TEMPO and reducing cellulose degradation in TEMPO mediated oxidation of cellulose has not been reported. 
In this work, a recoverable acrylamide-vinylamine copolymer immobilized TEMPO (P(AM-co-VAm)-T) catalyst for selective oxidation of cellulose was developed. Polyacrylamide (PAM) was prepared by radical polymerization of acrylamide (AM) and degraded using the Hofmann reaction to obtain acrylamide-vinylamine copolymer called $\mathrm{P}(\mathrm{AM}-\mathrm{co}-\mathrm{VAm})$. The $-\mathrm{NH}_{2}$ groups in $\mathrm{P}(\mathrm{AM}-\mathrm{co}-\mathrm{VAm})$ were reacted with the carbonyl groups in 4-oxo-TEMPO to obtain P(AM-co-VAm)-T with different molecular weights and TEMPO loading degrees. These catalysts were applied to selectively oxidize cellulose C6 primary hydroxyl groups to carboxyl groups in order to produce oxidized cellulose products with high carboxyl contents and low degradation degrees. Effects of the structure of P(AM-co-VAm)-T on the cellulose oxidation degree and cellulose degradation degree were discussed. The catalytic oxidation mechanism and the recycling performance were also studied.

\section{Experimental}

Materials

The following materials were purchased from Aladdin Industrial Corporation (China) and used without further purification: Acrylamide (AM, 99\%); 2,2'-azobis(2-methylpropionitrile) (AIBN, 99\%); 2,2,6,6tetramethyl-4-piperidone (99\%); sodium tungstate dihydrate $\left(\mathrm{Na}_{2} \mathrm{WO}_{4}, 99.5 \%\right)$; aqueous $\mathrm{H}_{2} \mathrm{O}_{2}$ solution (30\%); ethylene diamine tetraacetic acid (EDTA, $99.5 \%)$; potassium carbonate $\left(\mathrm{K}_{2} \mathrm{CO}_{3}, 99 \%\right)$; sodium cyanoborohydride ( $\left.\mathrm{NaBH}_{3} \mathrm{CN}, 95 \%\right)$; $\mathrm{NaBr}(99 \%)$; microcrystalline powders (99.3\%, wood-derived, average particle size of $50 \mu \mathrm{m}) ; \mathrm{NaClO}$ aqueous solution (5\%).

Synthesis of PAM

PAM with high molecular weight $(M n=20000)$ was prepared by solution polymerization (Achari et al. 1993). Under $\mathrm{N}_{2}$ atmosphere, $A M(10 \mathrm{~g}, 0.14 \mathrm{~mol})$ and isopropanol $(10 \mathrm{~mL}, 0.26 \mathrm{~mol})$ were dissolved in water $(1 \mathrm{~L})$ with mechanical stirring. $\mathrm{Na}_{2} \mathrm{~S}_{2} \mathrm{O}_{8}(0 . \mathrm{g}, 0.4 \mathrm{mmol})$ in water $(10 \mathrm{~mL})$ was added and the polymerization was then carried out for $1 \mathrm{~h}$ at $65^{\circ} \mathrm{C}$. The product was isolated by precipitation from methanol, and then dried to obtain PAM with $\mathrm{Mn}=20000$.

PAM with low molecular weight $(M n=7000)$ was prepared by precipitation polymerization (Wang and Wu 2002). Under $\mathrm{N}_{2}$ atmosphere, AM (10 g, $\left.0.14 \mathrm{~mol}\right)$, AlBN $(0.2 \mathrm{~g}, 1.22 \mathrm{mmol})$ and ethanol $(100 \mathrm{~mL})$ were added to a $250 \mathrm{~mL}$ three-necked flask with magnetic stirring at $60^{\circ} \mathrm{C}$. The reaction mixture was continually stirred for $2.5 \mathrm{~h}$. The reaction mixture was then cooled to room temperature. The resulting solids were filtrated, washed with ethanol and then dried to obtain PAM with $\mathrm{Mn}=7000$.

Preparation of $\mathrm{P}(\mathrm{AM}-\mathrm{co}-\mathrm{VAm})$ using the Hofmann reaction

A typical degradation of PAM using the Hofmann reaction was carried out to prepare P(AM-coVAm) (Achari et al. 1993): A mixture of $5 \% \mathrm{NaClO}(8.83 \mathrm{~mL}, 12.5 \mathrm{mmol})$ and $15 \mathrm{M} \mathrm{NaOH}(1 \mathrm{~mL}, 0.015$ $\mathrm{mol})$ in a $100 \mathrm{~mL}$ three-necked flask was cooled to $-10{ }^{\circ} \mathrm{C}$. A PAM aqueous solution $(6.8 \mathrm{wt} . \%, 14.7 \mathrm{~mL})$ was cooled to $0{ }^{\circ} \mathrm{C}$ and added dropwise to the above reaction mixture with magnetic stirring. After $1.5 \mathrm{~h}$, 
$11 \mathrm{M} \mathrm{NaOH}(32 \mathrm{~mL}, 0.352 \mathrm{mmol})$ cooled to $-10^{\circ} \mathrm{C}$ was added dropwise. The reaction was performed at $-10{ }^{\circ} \mathrm{C}$ for $0.5 \mathrm{~h}$ and then maintained at $0{ }^{\circ} \mathrm{C}$ for $17 \mathrm{~h}$. $\mathrm{P}(\mathrm{AM}-\mathrm{Co}-\mathrm{VAm})$ was isolated by precipitation from methanol, and then washed and dried.

Preparation of P(AM-co-VAm)-T

4-oxo-TEMPO was prepared by oxidizing 2,2,6,6-tetramethyl-4-piperidone using $\mathrm{Na}_{2} \mathrm{WO}_{4} / \mathrm{H}_{2} \mathrm{O}_{2}$ /EDTA system (Liu et al. 2018b). P(AM-co-VAm)-T was prepared by means of the reductive amination reaction between the primary amine groups in $\mathrm{P}(\mathrm{AM}-\mathrm{co}-\mathrm{VAm})$ and the carbonyl groups in 4-oxo-TEMPO. The typical process was as follows: P(AM-co-VAm) (containing $\left.24 \mathrm{mmol}-\mathrm{NH}_{2}\right)$, 4-oxo-TEMPO $(2.043 \mathrm{~g}, 12$ $\mathrm{mmol}$ ) and methanol $(20 \mathrm{~mL})$ were added to a $50 \mathrm{~mL}$ three-necked flask with magnetic stirring. $\mathrm{NaBH}_{3} \mathrm{CN}$ $(1.131 \mathrm{~g}, 18 \mathrm{mmol})$ was added to the reaction mixture at $40^{\circ} \mathrm{C}$. The reaction was carried out for $120 \mathrm{~h}$ and $\mathrm{P}(\mathrm{AM}-\mathrm{CO}-\mathrm{VAm})-\mathrm{T}$ was obtained by filtration from methanol.

Selective oxidation of cellulose with P(AM-co-VAm)-T as catalyst

The oxidation process was carried out according to the previously published method (Liu et al. 2017). A mixture of cellulose (2.5 g), P(AM-co-VAm)-T (containing $0.59 \mathrm{mmol}$ TEMPO), $\mathrm{NaBr}(0.07 \mathrm{~g}, 0.68 \mathrm{mmol}$ ), water $(188 \mathrm{~mL})$ and $5 \% \mathrm{NaClO}$ solution $(5 \mathrm{mmol} / \mathrm{g}$ cellulose) were added to a $250 \mathrm{~mL}$ three-necked flask at $25^{\circ} \mathrm{C}$. The $\mathrm{pH}$ of the mixture was maintained at 10.5 by adding $0.5 \mathrm{M} \mathrm{NaOH}$. After $24 \mathrm{~h}$, the reaction was quenched by adding $10 \mathrm{~mL}$ ethanol. The oxidized products included two types: high-molecularweight oxidized product (water-insoluble) and low-molecular-weight degraded product (water-soluble). The water-insoluble high-molecular-weight oxidized product was the main product of this study, which was referred to as oxidized cellulose in this paper. The oxidized cellulose was separated by centrifugation and dried by lyophilization. The supernatant was concentrated and then applied again as the reaction system for the next catalytic oxidation cycle. After 10 recycles, inorganic salts and degraded products were removed by dialysis the supernatant. The obtained aqueous solution was precipitated into methanol to recovery P(AM-co-VAm)-T for further oxidation cycle.

Post-reduction treatment of oxidized cellulose

The oxidized cellulose sample $(1 \mathrm{~g})$ was dispersed in a $0.01 \mathrm{M}$ aqueous $\mathrm{NaBH}_{4}$ solution $(50 \mathrm{~mL})$ with magnetic stirring for $6 \mathrm{~h}$ at $25^{\circ} \mathrm{C}$. The product was centrifuged and immersed in $1 \mathrm{M} \mathrm{cold} \mathrm{CH}_{3} \mathrm{COOH}$ for 1 h. It was then centrifuged and washed with water. The reduced oxidized cellulose products were freezedried (Nabar and Shenai 1970; Shennai and Sudan 1972).

\section{Characterization}

The structures of PAM, P(AM-co-VAm), P(AM-co-VAm)-T and oxidized cellulose were characterized using Fourier transform infrared spectroscopy (FT-IR, Nicolet 6700, Thermo Nicolet, USA). The TEMPO loading degree of $\mathrm{P}(\mathrm{AM}-\mathrm{Co}-\mathrm{VAm})-\mathrm{T}$ was tested by the electron spin resonance (ESR, Bruker EMX-10). 
The $-\mathrm{NH}_{2}$ content of $\mathrm{P}(\mathrm{AM}-\mathrm{co}-\mathrm{VAm})$ was determined by conductometric titration (Hu et al. 2004). P(AM-coVAm) was dissolved to an aqueous $\mathrm{HCl}$ solution to get $\mathrm{P}(\mathrm{AM}-\mathrm{co}-\mathrm{VAmHCl}) .80 \mathrm{mg}$ of $\mathrm{P}(\mathrm{AM}-\mathrm{Co}-\mathrm{VAmHCl})$ was completely dissolved in $100 \mathrm{~mL}$ water. It was then titrated with $0.1 \mathrm{M} \mathrm{AgNO}_{3}$ at room temperature until the inflection point appeared. The content of $-\mathrm{NH}_{2}$ in $\mathrm{P}(\mathrm{AM}-\mathrm{co}-\mathrm{VAm})$ was calculated using the formula (1):

$\mathrm{cV} / 1000=\mathrm{mx} /[79.5 \mathrm{x}+71(1-\mathrm{x})]$

where: $\mathrm{x}$--degree of amination of $\mathrm{P}(\mathrm{AM}-\mathrm{co}-\mathrm{VAm}), \%$; m--mass of $\mathrm{P}(\mathrm{AM}-\mathrm{co}-\mathrm{VAmHCl}), \mathrm{g}$; $\mathrm{V}$-volume of consumed $0.1 \mathrm{M} \mathrm{AgNO}_{3}, \mathrm{~mL}$; C--concentration of $0.1 \mathrm{M} \mathrm{AgNO}_{3}$ solution, $\mathrm{mol} / \mathrm{L} ; 79.5,71$--unit molar mass of PVAmHCl and PAM, $\mathrm{g} / \mathrm{mol}$.

The relative number-average molecular weights $(\mathrm{Mn})$ and polydispersity index (PDI) of PAM, P(AM-coVAm) and P(AM-co-VAm)-T were measured by gel permeation chromatography (GPC, Waters 1515, USA) with a refractive index detector in water (containing $0.02 \% \mathrm{NaN}_{3}$ ) at $35^{\circ} \mathrm{C}$ using a calibration curve from polyethylene glycol (PEG) standards.

The carboxyl content of oxidized cellulose was determined using the previously reported conductivity titration method (Liu et al. 2017). The average degree of viscosity of polymerization (DPv) of cellulose in a copper ethylenediamine solution was determined using a capillary viscometer (Saito and Isogai 2004). Three replicates were performed for each measurement and the average value was used. The degradation degree was estimated using the formula (2):

Degradation degree $=\left(\mathrm{DPv}_{0}-\mathrm{DPv_{1 }}\right) / \mathrm{DPv_{0 }}$

where: $\mathrm{DPv} \mathrm{v}_{0}-\mathrm{DPv}$ of fresh cellulose; $\mathrm{DPv} \mathrm{v}_{1}-\mathrm{DPv}$ of oxidized cellulose.

\section{Results And Discussion}

Preparation of P(AM-co-VAm)-T

As shown in Fig.1, P(AM-co-VAm) was prepared by means of Hofmann degradation of PAM. Then, P(AMco-VAm)-T was obtained through the reaction between $-\mathrm{NH}_{2}$ groups in $\mathrm{P}(\mathrm{AM}-\mathrm{co}-\mathrm{VAm})$ and carbonyl groups in 4-oxo-TEMPO. The success synthesis of $\mathrm{P}(\mathrm{AM}-\mathrm{Co}-\mathrm{VAm})$ was confirmed by FT-IR and the $-\mathrm{NH}_{2}$ content was estimated by conductometric titration. P(AM-co-VAm)-T was also confirmed by FT-IR and the TEMPO loading degree was estimated using the electron spin resonance.

Fig. 2 is the FT-IR spectra of PAM, 4-oxo-TEMPO, P(AM-co-VAm) with $72 \%$ amination degree and P(AM-coVAm)-T with 55\% TEMPO loading degree. In the spectrum of PAM, the absorption peaks of $3431 \mathrm{~cm}^{-1}$ and $1607 \mathrm{~cm}^{-1}$ were attributed to the stretching vibration of $\mathrm{N}-\mathrm{H}$ and $\mathrm{C}=\mathrm{O}$ of the acylamino groups. Compared with PAM, the absorption peak of $1509 \mathrm{~cm}^{-1}$ corresponding to the bending vibration of $\mathrm{N}-\mathrm{H}$ of $-\mathrm{NH}_{2}$ was found in the spectrum of $\mathrm{P}(\mathrm{AM}-\mathrm{co}-\mathrm{VAm})$. Furthermore, the intensity of the characteristic absorption peak 
of $\mathrm{C}=0$ at $1608 \mathrm{~cm}^{-1}$ was significantly reduced. In the spectrum of $\mathrm{P}(\mathrm{AM}-\mathrm{co}-\mathrm{VAm})-\mathrm{T}$, the characteristic absorption peaks of N-O at $1244 \mathrm{~cm}^{-1}, \mathrm{C}-\mathrm{N}$ at $1360 \mathrm{~cm}^{-1}$ and $-\mathrm{CH}_{3}$ at $2924 \mathrm{~cm}^{-1}$ of TEMPO were found.

The molecular weights of PAM, P(AM-co-VAm) and P(AM-co-VAm)-T were estimated by GPC with a refractive index detector using a calibration curve from PEG standards. It should be emphasized that this method can only measure the relative molecular weights of these polymers, because the radii of gyration of them must be different from those of PEG. However, it can still be used to characterize the trend of molecular weight change in the preparation of macromolecular catalyst. From Fig. 3 and Table 1, it was clearly seen that the molecular weight of P(AM-co-VAm) obtained by Hofmann degradation of PAM was significantly lower than its precursor of PAM. Compared with the carrier of P(AM-co-VAm), the molecular weight of macromolecular catalyst with $16 \%$ TEMPO loading degree (P(AM-co-VAm)-P-T-16) was increased accordingly. As the TEMPO loading increased from $16 \%$ to $55 \%$, the molecular weight of macromolecular catalyst (P(AM-co-VAm)-P-T-55) increased correspondingly. These results further confirmed the successful preparation of P(AM-co-VAm)-T.

Table 1 Mn and PDI of PAM, P(AM-co-VAm) and P(AM-co-VAm)-T

\begin{tabular}{ccc}
\hline & Mn & PDI \\
\hline PAM & 7000 & 1.02 \\
\hline P(AM-co-VAm) & 5200 & 1.05 \\
\hline P(AM-co-VAm)-P-T-16 & 5600 & 1.07 \\
\hline P(AM-co-VAm)-P-T-55 & 6300 & 1.04
\end{tabular}

In order to systematically study effects of the structure of P(AM-co-VAm)-T on the performance of selective oxidation of cellulose $\mathrm{C} 6$ primary hydroxyl groups to carboxyl groups, P(AM-co-VAm)-T catalysts with different molecular weights and TEMPO loading degrees were designed and synthesized (Table 2). For the solution polymerization, the obtained PAM was with high molecular weight $(M n=20000)$. The increase of the molar ratio between 4-oxo-TEMPO and - $\mathrm{NH}_{2}$ in $\mathrm{P}(\mathrm{AM}-\mathrm{co}-\mathrm{VAm})$ seemed to improve the TEMPO loading degree of P(AM-co-VAm)-T. P(AM-co-VAm)-T had good water solubility with EMPO loading degree of about $20 \%$. However, the macromolecular catalyst was almost water-insoluble when the TEMPO loading degree was increased to about $40 \%$. For synthesizing a water-soluble P(AM-co-VAm)T catalyst with high TEMPO loading degree, the precipitation polymerization was used to prepare PAM with low molecular weight $(M n=7000)$. With it as carrier, the prepared P(AM-co-VAm)-T with $57 \%$ TEMPO loading degree still had good water solubility.

Table 2 Characteristics of P(AM-co-VAm)-T prepared in this work 


\begin{tabular}{|c|c|c|c|c|c|c|}
\hline $\begin{array}{c}\mathrm{P}(\mathrm{AM}-\mathrm{co}-\mathrm{VAm})- \\
\text { T catalysts }\end{array}$ & $\begin{array}{l}\text { Mn of } \\
\text { PAM }\end{array}$ & $\begin{array}{c}\text { Amination } \\
\text { degree } \\
(\%)\end{array}$ & $\begin{array}{c}\text { Water } \\
\text { solubility }\end{array}$ & $\begin{array}{c}\text { - } \mathrm{NH}_{2} \text { in P(AM-Co- } \\
\text { VAm)/4-oxo-TEMPO }\end{array}$ & $\begin{array}{c}\text { TEMPO } \\
\text { loading } \\
\text { degree } \\
(\%)\end{array}$ & $\begin{array}{c}\text { TEMPO } \\
\text { loading } \\
\text { amount } \\
(\mathrm{mmol} / \mathrm{g})\end{array}$ \\
\hline $\begin{array}{c}\mathrm{P}(\mathrm{AM}-\mathrm{Co}-\mathrm{VAm})- \\
\text { S-T-19 }\end{array}$ & 20000 & 75.7 & soluble & $8: 2$ & 19.1 & 2.42 \\
\hline $\begin{array}{c}\text { P(AM-Co-VAm)- } \\
\text { S-T-20 }\end{array}$ & 20000 & 75.7 & soluble & $8: 3$ & 20.2 & 2.52 \\
\hline $\begin{array}{c}\text { P(AM-co-VAm)- } \\
\text { S-T-21 }\end{array}$ & 20000 & 72.3 & soluble & $8: 4$ & 21.4 & 2.61 \\
\hline $\begin{array}{c}\mathrm{P}(\mathrm{AM}-\mathrm{CO}-\mathrm{VAm})- \\
\text { S-T-40 }\end{array}$ & 20000 & 77.4 & insoluble & $8: 6$ & 39.8 & 3.65 \\
\hline $\begin{array}{c}\text { P(AM-Co-VAm)- } \\
\text { S-T-43 }\end{array}$ & 20000 & 77.4 & insoluble & $8: 8$ & 43.4 & 3.79 \\
\hline $\begin{array}{c}\text { P(AM-co-VAm)- } \\
\text { P-T-16 }\end{array}$ & 7000 & 72.0 & soluble & $8: 4$ & 15.6 & 2.12 \\
\hline $\begin{array}{c}\text { P(AM-Co-VAm)- } \\
\text { P-T-29 }\end{array}$ & 7000 & 72.0 & soluble & $8: 5$ & 28.5 & 3.08 \\
\hline $\begin{array}{c}\text { P(AM-Co-VAm)- } \\
\text { P-T-31 }\end{array}$ & 7000 & 72.0 & soluble & $8: 6$ & 30.6 & 3.20 \\
\hline $\begin{array}{c}\text { P(AM-co-VAm)- } \\
\text { P-T-37 }\end{array}$ & 7000 & 72.3 & soluble & $8: 8$ & 36.7 & 3.52 \\
\hline $\begin{array}{c}\mathrm{P}(\mathrm{AM}-\mathrm{co}-\mathrm{VAm})- \\
\mathrm{P}-\mathrm{T}-41\end{array}$ & 7039 & 73.1 & soluble & $8: 7$ & 40.8 & 3.70 \\
\hline $\begin{array}{c}\text { P(AM-co-VAm)- } \\
\text { P-T-55 }\end{array}$ & 7000 & 73.1 & soluble & $8: 8$ & 55.1 & 4.19 \\
\hline $\begin{array}{c}\text { P(AM-co-VAm)- } \\
\text { P-T-57 }\end{array}$ & 7000 & 72.3 & soluble & $8: 12$ & 56.9 & 4.25 \\
\hline
\end{tabular}

Note: Meaning of symbols in P(AM-co-VAm)-T: S means PAM is prepared by solution polymerization. $\mathrm{P}$ means PAM is prepared by precipitation polymerization. The number is the TEMPO loading degree. Selective catalytic oxidation of cellulose using P(AM-co-VAm)-T as catalyst

The selective oxidation of cellulose was carried out with $\mathrm{P}(\mathrm{AM}-\mathrm{Co}-\mathrm{VAm})-\mathrm{T}$ as the catalyst, $\mathrm{NaBr}$ as the promoter and $\mathrm{NaClO}$ as the oxidant $(5 \mathrm{mmol} / \mathrm{g}$ cellulose) in water at $\mathrm{pH}=10.5$. The characteristic peaks of P(AM-co-VAm)-T were not found in the FT-IR spectrum of P(AM-co-VAm)-T oxidized cellulose (Fig. 4). Furthermore, in the following recovery experiments, it was found that almost all catalysts (over 96\%) could be recovered by dialysis and precipitation method. These results indicated that no P(AM-co-VAm)-T remained on the oxidized cellulose. This may be due to that the oxidized cellulose is difficult to form polyion complexes with amine groups of $\mathrm{P}(\mathrm{AM}-\mathrm{co}-\mathrm{VAm})-\mathrm{T}$ in strong alkali conditions.

Sharp peaks at $1615 \mathrm{~cm}^{-1}$ corresponding to -COONa were present in oxidized cellulose samples. The intensity of peak at $1615 \mathrm{~cm}^{-1}$ of P(AM-co-VAm)-T oxidized cellulose was slightly weaker than that of TEMPO oxidized cellulose, indicating that P(AM-co-VAm)-T could also give high cellulose oxidation 
degree. The carboxyl contents of oxidized cellulose products were quantitatively determined by conductometric titration as shown in Fig.5. It was found that the carboxyl content of oxidized cellulose prepared by P(AM-co-VAm)-T with a high molecular weight PAM $(M n=20000)$ as carrier increased with the increase of TEMPO loading degree. When the TEMPO loading degree was $43 \%$, the carboxyl content of oxidized cellulose reached $64.5 \%$ of the free TEMPO level. However, the water solubility became poor as the TEMPO loading increasing, which complicated the catalyst separation from the oxidized product. TEMPO loading degree seemed to have little effect on the catalytic performance of P(AM-co-VAm)-T with a low molecular weight PAM ( $M n=7000)$ as carrier. As the TEMPO loading increased from $16 \%$ to $57 \%$, the carboxyl group contents of oxidized cellulose samples were close, i.e. about 1-1.1 mmol/g, which was equivalent to $68 \%-76 \%$ of the free TEMPO level $(1.46 \mathrm{mmol} / \mathrm{g})$. This may be due to the excellent water solubility of macromolecular catalyst with low molecular weight, making the catalyst have close diffusion ability to that of free TEMPO. These results indicated that the molecular weight had a significant effect on the catalytic performance of macromolecular catalyst.

Comparison of the catalytic performance of $\mathrm{P}(\mathrm{AM}-\mathrm{co}-\mathrm{VAm})-\mathrm{T}$ with other reported water-soluble macromolecular TEMPO catalysts for selective oxidation of cellulose

A comparison of catalytic performance of $\mathrm{P}(\mathrm{AM}-\mathrm{co}-\mathrm{VAm})-\mathrm{T}$ with other reported water-soluble macromolecular TEMPO catalysts for selective oxidation of cellulose are shown in Fig.6. The carboxyl content of obtained oxidized cellulose was $1.45 \mathrm{mmol} / \mathrm{g}$ for G1.0 PAMAM-T30 (Liu et al. 2018b), 1.114 $\mathrm{mmol} / \mathrm{g}$ for P(AM-co-VAm)-P-T-55 (Fig. 6a) and $0.864 \mathrm{mmol} / \mathrm{g}$ for P(AA-co-TA)-26.43 (Liu et al. 2018a), equivalent to $99.3 \%, 76.3 \%$, and $59.2 \%$ of the free TEMPO level, respectively.

Fig.6(b) shows that the oxidation rates of macromolecular catalysts were comparable to free TEMPO in the initial stage of oxidation. Thereafter, PAMAM-TEMPO and TEMPO tended to be stable. After $1 \mathrm{~h}$, the rates for $\mathrm{P}(\mathrm{AM}-\mathrm{Co}-\mathrm{VAm})-\mathrm{T}$ and $\mathrm{P}(\mathrm{AA}-\mathrm{co}-\mathrm{TA})$ slowed down. The oxidation rate of $\mathrm{P}(\mathrm{AM}-\mathrm{co}-\mathrm{VAm}-\mathrm{T})$ was faster than that of $P(A A-c o-T A)$. These results are consistent with the above carboxyl content results. The catalytic oxidation performances of macromolecular catalysts should be related to the chain structure, charge type, TEMPO loading and space size.

In the TEMPO/NaBr/NaClO system, the cellulose oxidation is a diffusion-controlled reaction in which the catalysts pass through the pores of cellulose and to oxidize it. The average pore volume is in the range of about 2-20 nm (Hubbe et al. 2007). A non-charged hydrophobic TEMPO with no special affinity for cellulose can shuttle freely inside the cellulose. When converted into positively charged TEMPO ${ }^{+}(\mathrm{Liu}$ 2012), they attract each other with carboxylated cellulose and are prone to selective oxidation of cellulose, so that the oxidation perfornance is excellent. The negatively charged P(AA-co-TA) repels with carboxylated cellulose, resulting in a poor porformance of oxidized cellulose (Fig.7). PAMAM-TEMPO or $\mathrm{P}(\mathrm{AM}-\mathrm{co}-\mathrm{VAm})-\mathrm{T}$ has the positive charge of TEMPO ${ }^{+}$and the $-\mathrm{NH}_{2}$ groups in the carrier of PAMAM or P(AM-co-VAm), so they are more easily adsorbed onto cellulose. G1.0 PAMAM-TEMPO with a size of about $1.4 \mathrm{~nm}$ can enter cellulose micro-pores freely and gives a similar cellulose oxidation degree with free TEMPO. P(AM-co-VAm)-T with a size of about $15 \mathrm{~nm}$ tends to be absorbed on the cellulose surface 
by electrostatic action for oxidation reaction, and is difficult to enter the interior. Despite this, the catalytic performance of $\mathrm{P}(\mathrm{AM}-\mathrm{co}-\mathrm{VAm})-\mathrm{T}$ is still satisfactory and higher than that of other reported polymer supported TEMPO catalysts.

Free TEMPO can oxidize both exterior and interior parts of cellulose, resulting in the serious depolymerization of cellulose. The DPv of raw cellulose was about 160 , and the value of TEMPO oxidized cellulose was significantly decreased to about 55-72 (Table 3), equivalent to $61 \%-66 \%$ degradation degree. However, the DPv of P(AM-co-VAm)-T oxidized cellulose was much higher than that of free TEMPO oxidized cellulose and the value was in the range of $117-126$, equivalent to $21 \%-27 \%$ degradation degree. In addition, the mass yield of P(AM-co-VAm)-T oxidized cellulose was higher than that of free TEMPO.

Table 3 The carboxyl contents, DPv and mass yields of TEMPO oxidized cellulose and P(AM-co-VAm)-T oxidized cellulose

\begin{tabular}{cccc}
\hline & $\begin{array}{c}\text { Carboxyl content } \\
\mathrm{mmog} / \mathrm{g}\end{array}$ & $\mathrm{DPv}$ & $\begin{array}{c}\text { Mass yield } \\
\%\end{array}$ \\
\hline TEMPO oxidized cellulose & 0.489 & 72.4 & 90.2 \\
\cline { 2 - 4 } & 0.937 & 57.3 & 90.4 \\
\cline { 2 - 4 } & 1.331 & 55.3 & 90.6 \\
\hline P(AM-co-VAm)-T oxidized cellulose & 0.481 & 124.1 & 96.4 \\
\cline { 2 - 4 } & 0.642 & 125.7 & 96.0 \\
\cline { 2 - 4 } & 0.987 & 117.4 & 95.6 \\
\cline { 2 - 4 } & 1.019 & 117.7 & 95.4 \\
\cline { 2 - 4 } & 1.114 & 119.2 & 95.6 \\
\hline
\end{tabular}

When other macromolecular catalysts were used, the depolymerization of cellulose seemed to also be suppressed (Fig. 8). The DPv of PAMAM-TEMPO oxidized cellulose was reduced to 90-115 with a degradation degree of $28 \%-44 \%$. The value of P(AA-co-TA) oxidized cellulose was about $75-94$ with a degradation degree of $41 \%-53 \%$. One possible reason is that the macromolecular TEMPO mediated oxidation is mainly restricted to the exterior surfaces of porous cellulose, resulting in that the degradation of cellulose is inhibited to some extent. However, $\mathrm{P}(\mathrm{AM}-\mathrm{co}-\mathrm{VAm})-\mathrm{T}$ causes the least degradation of cellulose, even if its size is similar to that of P(AA-co-TA). Therefore, there should be other factors affecting the cellulose degradation for macromolecular catalysts. In order to reveal this, a comparative experiment was conducted. P(AM-co-VAm) and 4-oxo-TEMPO were physically mixed according to their respective content in the synthesis of $\mathrm{P}(\mathrm{AM}-\mathrm{Co}-\mathrm{VAm})-\mathrm{T}$, and then added to the cellulose oxidation system. It was found that the cellulose degradation degree was consistent with the free TEMPO system. Therefore, it can be concluded that P(AM-co-VAm)-T, rather than P(AM-co-VAm), plays a key role in alleviating the degradation of cellulose in the oxidation process.

Shinoda et al (Shinoda et al. 2012) found that TEMPO oxidized cellulose generally contained small amounts of $\mathrm{C} 6$ aldehydes and $\mathrm{C} 2 / \mathrm{C} 3$ ketones. These $\mathrm{C} 6$ aldehydes and $\mathrm{C} 2 / \mathrm{C} 3$ ketones caused depolymerization when cellulose was dissolved in alkaline $0.5 \mathrm{M}$ copper for DPv determination. Postreduction with $\mathrm{NaBH}_{4}$ at $\mathrm{pH}=10$ can remove the $\mathrm{C} 6$ aldehydes and $\mathrm{C} 2 / \mathrm{C} 3$ ketones that form hemiacetal 
bonds between fibers during the drying process. Fig. 9 shows DPv results of oxidized cellulose products obtained with different catalysts before and post reduction treatment. The DPV of TEMPO oxidized cellulose was largely increased after reduction, indicating that this oxidized cellulose contained a large amount of $\mathrm{C} 6$ aldehydes and $\mathrm{C} 2 / \mathrm{C} 3$ ketones. The values of PAMAM-TEMPO oxidized cellulose (Liang et al. 2020) and $P(A A-c o-T A)$ oxidized cellulose were also increased to some extent after reduction. Interestingly, $\mathrm{P}(\mathrm{AM}-\mathrm{co}-\mathrm{VAm})-\mathrm{T}$ oxidized cellulose had almost the same $\mathrm{DPv}$ before and after reduction, indicating that few side reactions occurred during $\mathrm{P}(\mathrm{AM}-\mathrm{co}-\mathrm{VAm})-\mathrm{T}$ mediated oxidation of cellulose. It seems that $\mathrm{P}(\mathrm{AM}-\mathrm{Co}-\mathrm{VAm})-\mathrm{T}$ can prevent the formation of $\mathrm{C} 6$ aldehydes and $\mathrm{C} 2 / \mathrm{C} 3$ ketones by side reactions, indicating that $\mathrm{P}(\mathrm{AM}-\mathrm{Co}-\mathrm{VAm})-\mathrm{T}$ has high oxidation selectivity. This should be another main reason that it can efficiently inhibit the degradation of cellulose.

The recycling performance of $\mathrm{P}(\mathrm{AM}-\mathrm{co}-\mathrm{VAm})-\mathrm{T}$

P(AM-co-VAm)-T, as a water-soluble macromolecular TEMPO catalyst, should be present in the supernatant after the oxidation reaction. Therefore, we designed the catalyst recycling scheme shown in Fig.10. The supernatant containing P(AM-co-VAm)-T, inorganic salts and degraded products was concentrated and reused for next oxidation cycle. After 10 recycles, inorganic salts and degraded products were removed by dialysis the supernatant. The obtained aqueous solution was precipitated into methanol to recovery $\mathrm{P}(\mathrm{AM}-\mathrm{co}-\mathrm{VAm})$-T for further oxidation cycle. Over $96 \% \mathrm{P}(\mathrm{AM}-\mathrm{co}-\mathrm{VAm})-\mathrm{T}$ was recovered, and the color and state were consistent with the original catalyst. As shown in Fig.11, the characteristic peaks corresponding to TEMPO moieties still existed in recovered P(AM-co-VAm)-T and the TEMPO loading degree (54.7\%) was almost the same as the fresh P(AM-co-VAm)-T-55. Fig.12 shows that this recovered $\mathrm{P}(\mathrm{AM}-\mathrm{co}-\mathrm{VAm})-\mathrm{T}$ can still give a good oxidation performance (cycle 12-15).

\section{Conclusions}

Water-soluble P(AM-co-VAm)-T catalysts with different molecular weights and TEMPO loading degrees were prepared and applied to selective catalytic oxidation of cellulose. Both the molecular weight and TEMPO loading degree of P(AM-co-VAm)-T had an effect on catalytic performance. The catalytic performance was up to $76 \%$ of the free TEMPO level and did not decrease after recycling. Furthermore, $\mathrm{P}(\mathrm{AM}-\mathrm{co}-\mathrm{VAm})-\mathrm{T}$ could effectively alleviate the degradation of oxidized cellulose. The degradation degree of P(AM-co-VAm)-T oxidized cellulose was $21 \%-27 \%$, which was much lower than that of free TEMPO (61\%-66\%), and other macromolecular TEMPO catalysts, such as P(AA-co-TA) (41\%-53\%) and PAMAMTEMPO (28\%-44\%). P(AM-co-VAm)-T with positive charge and suitable size can effectively avoid the formation of $\mathrm{C} 6$ aldehydes and $\mathrm{C} 2 / \mathrm{C} 3$ ketones by side reactions and make the oxidation mainly restricted to the exterior surfaces of porous cellulose, resulting in a significant reduction in the degradation of cellulose.

\section{Declarations}

Acknowledgements

Page 12/25 
This study was supported by High-end Talent Grant of Hebei Province in China (No. [2019]63) and Natural Science Foundation of Hebei Province (CN) (No. B2020208032). We express our heartfelt thanks for the support.

Funding This study was funded by High-end Talent Grant of Hebei Province in China (No. [2019]63) and Natural Science Foundation of Hebei Province (CN) (No. B2020208032).

\section{Compliance with ethical standards}

Conflict of interest The authors declare that they have no conflict of interest.

Ethical approval This article does not contain any studies with human participants or animals performed by any of the authors.

\section{References}

Achari AE, Coqueret X, Lablache-Combier A, Loucheux C (1993) Preparation of polyvinylamine from polyacrylamide: a reinvestigation of the hofmann reaction. Die Makromolekulare Chemie. Macromolecular Chemistry and Physics 194:1879-1891. https://doi.org/10.1002/macp.1993.021940703

Araki J, lida M (2016) Surface carboxylation of cellulose nanowhiskers using mPEG-TEMPO: its recovery and recycling. Polymer Journal 48:1029-1033. https://doi.org/10.1038/pj.2016.65

Araki J, Wada M, Kuga S, Okano T (1998) Flow properties of microcrystalline cellulose suspension prepared by acid treatment of native cellulose. Colloids and Surfaces A: Physicochemical and Engineering Aspects 142:75-82. https://doi.org/10.1016/S0927-7757(98)00404-X

Biliuta G, Fras L, Drobota M, Persin Z, Kreze T, Stana-Kleinschek K, Ribitsch V, Harabagiu V, Coseri S (2013) Comparison study of TEMPO and phthalimide-N-oxyl (PINO) radicals on oxidation efficiency toward cellulose. Carbohydrate polymers 91:502-507. https://doi.org/10.1016/j.carbpol.2012.08.047

Coseri S, Nistor G, Fras L, Strnad S, Harabagiu V, Simionescu BC (2009) Mild and selective oxidation of cellulose fibers in the presence of N-hydroxyphthalimide. Biomacromolecules 10:2294-2299. https://doi.org/10.1021/bm9004854

Coseri S, Biliuta G, Simionescu BC, Stana-Kleinschek K, Ribitsch V, Harabagiu V (2013) Oxidized celluloseSurvey of the most recent achievements. Carbohydrate polymers 93:207-215. https://doi.org/10.1016/j.carbpol.2012.03.086

Coseri S, Biliuta G, Zemljič LF, Srndovic JS, Larsson PT, Strnad S, Kreže T, Naderi A, Lindström, T (2015) One-shot carboxylation of microcrystalline cellulose in the presence of nitroxyl radicals and sodium periodate. RSC advances 5:85889-85897. https://doi.org/10.1039/C5RA16183E 
Coseri S (2017) Cellulose: To depolymerize... or not to? Biotechnology advances 35:251-266. https://doi.org/10.1016/j.biotechadv.2017.01.002

Coseri S, Biliuta G, Simionescu BC (2018) Selective oxidation of cellulose, mediated by Nhydroxyphthalimide, under a metal-free environment. Polymer Chemistry 9:961-967. https://doi.org/10.1039/C7PY01710C

De Nooy AEJ, Besemer AC, Van Bekkum H (1994) Highly selective TEMPO mediated oxidation of primary alcohol groups in polysaccharides. Recueil des Travaux Chimiques des Pays-Bas 113:165-166. https://doi.org/10.1002/recl.19941130307

DiFlavio JL, Pelton R, Leduc M, Champ S, Essig M, Frechen T (2007) The role of mild TEMPO-NaBr-NaClO oxidation on the wet adhesion of regenerated cellulose membranes with polyvinylamine. Cellulose 14:257-268. https://doi.org/10.1007/s10570-006-9104-x

Fu Q, Sutherland A, Gustafsson E, Monsur Ali M, Soleymani L, Pelton R (2017) Relating redox properties of polyvinylamine-g-TEMPO/laccase hydrogel complexes to cellulose oxidation. Langmuir 33:7854-7861. https://doi.org/10.1021/acs.langmuir.7b01460

Fukuzumi H, Saito T, Iwata T, Kumamoto Y, Isogai A (2009) Transparent and high gas barrier films of cellulose nanofibers prepared by TEMPO-mediated oxidation. Biomacromolecules 10:162-165. https://doi.org/10.1021/bm801065u

Guo DM, An QD, Xiao ZY, Zhai SR, Shi Z (2017) Polyethylenimine-functionalized cellulose aerogel beads for efficient dynamic removal of chromium (VI) from aqueous solution. RSC advances 7:54039-54052. https://doi.org/10.1039/C7RA09940A

Hondo H, Saito T, Isogai A (2019) Preparation of oxidized celluloses in a $\mathrm{NaBr} / \mathrm{NaClO}$ system using 2azaadamantane $\mathrm{N}$-oxyl (AZADO) derivatives in water at pH 10. Cellulose 26:1479-1487. https://doi.org/10.1007/s10570-018-2177-5

Hu ZY, Zhang SF, Yang JZ (2004) Study on Some Properties of Aqueous Solutions of Poly (Vinylamine) Chloride. Polymer Materials Science and Engineering 20:107-110. http://dx.chinadoi.cn/10.3321/j.issn:1000-7555.2004.04.027

Hubbe MA, Rojas OJ, Lucia LA, Jung TM (2007) Consequences of the nanoporosity of cellulosic fibers on their streaming potential and their interactions with cationic polyelectrolytes. Cellulose 14:655-671. https://doi.org/10.1007/s10570-006-9098-4

Isogai, T.; Saito, T.; Isogai, A. TEMPO electromediated oxidation of some polysaccharides including regenerated cellulose fiber. Biomacromolecules 2010, 11(6), 1593-1599.

Isogai T, Saito T, Isogai A (2010) TEMPO electromediated oxidation of some polysaccharides including regenerated cellulose fiber. Biomacromolecules 11:1593-1599. https://doi.org/10.1021/bm1002575 
Isogai A, Saito T, Fukuzumi H (2011a) TEMPO-oxidized cellulose nanofibers. nanoscale 3:71-85. https://doi.org/10.1039/CONR00583E

Isogai T, Saito T, Isogai A (2011b) Wood cellulose nanofibrils prepared by TEMPO electro-mediated oxidation. Cellulose 18:421-431. https://doi.org/10.1007/s10570-010-9484-9

Isogai A, Hänninen T, Fujisawa S, Saito T (2018) Catalytic oxidation of cellulose with nitroxyl radicals under aqueous conditions. Progress in Polymer Science 86:122-148.

https://doi.org/10.1016/j.progpolymsci.2018.07.007

Jiang J, Ye W, Liu L, Wang Z, Fan Y, Saito T, Isogai A (2017) Cellulose nanofibers prepared using the TEMPO/laccase $/ \mathrm{O}_{2}$ system. Biomacromolecules 18:288-294.

https://doi.org/10.1021/acs.biomac.6b01682

Jin Y, Edler KJ, Marken F, Scott JL (2014) Voltammetric optimisation of TEMPO-mediated oxidations at cellulose fabric. Green Chemistry 16:3322-3327. https://doi.org/10.1039/C4GC00306C

Jun SH, Park SG, Kang NG (2019) One-pot method of synthesizing TEMPO-oxidized bacterial cellulose nanofibers using immobilized TEMPO for skincare applications. Polymers 11:1044.

https://doi.org/10.3390/polym11061044

Liang H, Cao M, Yang D, Sun T, Chu X, Liu S (2020) Polyamidoamine Immobilized TEMPO Mediated Oxidation of Cellulose: Effect of Macromolecular Catalyst Structure on the Reaction Rate, Oxidation Degree and Degradation Degree. Fibers and Polymers 21:1251-1258. https://doi.org/10.1007/s12221020-9859-y

Liu S, Xing Y, Han J, Tang E (2017) Catalytic oxidation of cellulose with a novel amphiphilic nitroxide block copolymer as a recoverable catalyst. Cellulose 24:3635-3644. https://doi.org/10.1007/s10570-017$1375-x$

Liu S, Sun T, Yang D, Cao M, Liang H (2018) Polyacrylic acid supported TEMPO for selective catalytic oxidation of cellulose: recovered by its pH sensitivity. Cellulose 25:5687-5696. https://doi.org/10.1007/s10570-018-2012-z

Liu S, Liang H, Sun T, Yang D, Cao M (2018) A recoverable dendritic polyamidoamine immobilized TEMPO for efficient catalytic oxidation of cellulose. Carbohydrate polymers 202:563-570. https://doi.org/10.1016/j.carbpol.2018.09.016

Liu J (2012) Mechanisms for cellulose-reactive polyvinylamine-graft-tempo adhesive (Doctoral dissertation). Ph.D. Thesis, McMaster University, Canada, http://hdl.handle.net/11375/12245

Liu J, Pelton R, Obermeyer JM, Esser A (2013) Laccase complex with polyvinylamine bearing grafted TEMPO is a cellulose adhesion primer. Biomacromolecules 14:2953-2960. 
Melone L, Punta C (2013) Metal-free aerobic oxidations mediated by N-hydroxyphthalimide. A concise review. Beilstein journal of organic chemistry 9:1296-1310. http://dx.doi.org/10.3762\%2Fbjoc.9.146

Nabar GM, Shenai VA (1970) Studies in chemically modified celluloses. III. Estimation of free carboxylic acid groups in oxycellulose. Journal of Applied Polymer Science 14:1215-1226.

https://doi.org/10.1002/app.1970.070140509

Pelton R, Ren P, Liu J, Mijolovic D (2011) Polyvinylamine-graft-TEMPO adsorbs onto, oxidizes, and covalently bonds to wet cellulose. Biomacromolecules 12:942-948. https://doi.org/10.1021/bm200101b

Pelton R (2014) Polyvinylamine: A tool for engineering interfaces. Langmuir 30:15373-15382. https://doi.org/10.1021/la5017214

Quintana E, Roncero MB, Vidal T, Valls C (2017) Cellulose oxidation by Laccase-TEMPO treatments. Carbohydrate polymers 157:1488-1495. https://doi.org/10.1016/j.carbpol.2016.11.033

Saito T, Isogai A (2004) TEMPO-mediated oxidation of native cellulose. The effect of oxidation conditions on chemical and crystal structures of the water-insoluble fractions. Biomacromolecules 5:1983-1989. https://doi.org/10.1021/bm0497769

Saito T, Shibata I, Isogai A, Suguri N, Sumikawa N (2005) Distribution of carboxylate groups introduced into cotton linters by the TEMPO-mediated oxidation. Carbohydrate polymers 61:414-419. https://doi.org/10.1016/j.carbpol.2005.05.014

Saito T, Nishiyama Y, Putaux JL, Vignon M, Isogai A (2006) Homogeneous suspensions of individualized microfibrils from TEMPO-catalyzed oxidation of native cellulose. Biomacromolecules 7:1687-1691. https://doi.org/10.1021/bm060154s

Saito T, Hirota M, Tamura N, Kimura S, Fukuzumi H, Heux L, Isogai A (2009) Individualization of nanosized plant cellulose fibrils by direct surface carboxylation using TEMPO catalyst under neutral conditions. Biomacromolecules 10:1992-1996. https://doi.org/10.1021/bm900414t

Saito T, Hirota M, Tamura N, Isogai A (2010) Oxidation of bleached wood pulp by TEMPO/ $\mathrm{NaClO} / \mathrm{NaClO}$ system: effect of the oxidation conditions on carboxylate content and degree of polymerization. Journal of wood science 56:227-232. https://doi.org/10.1007/s10086-009-1092-7

Shenai VA, Sudan RK (1972) Studies in chemically modified celluloses. IV. Lactones in chemically modified celluloses. Journal of Applied Polymer Science 16:545-550.

https://doi.org/10.1002/app.1972.070160301

Shi SX, Pelton R, Fu Q, Yang ST (2014) Comparing polymer-supported TEMPO mediators for cellulose oxidation and subsequent polyvinylamine grafting. Industrial \& Engineering Chemistry Research 53: 
Shibata I, Isogai A (2003) Depolymerization of cellouronic acid during TEMPO-mediated oxidation. Cellulose 10:151-158. https://doi.org/10.1023/A:1024051514026

Shinoda R, Saito T, Okita Y, Isogai A (2012) Relationship between length and degree of polymerization of TEMPO-oxidized cellulose nanofibrils. Biomacromolecules 13:842-849.

https://doi.org/10.1021/bm2017542

Takaichi S, Isogai A (2013) Oxidation of wood cellulose using 2-azaadamantane N-oxyl (AZADO) or 1methyl-AZADO catalyst in NaBr/NaClO system. Cellulose 20:1979-1988. https://doi.org/10.1007/s10570013-9932-4

Takaichi S, Hiraoki R, Inamochi T, Isogai A (2014) One-step preparation of 2, 3, 6-tricarboxy cellulose. Carbohydrate polymers 110:499-504. https://doi.org/10.1016/j.carbpol.2014.03.085

Tanaka R, Saito T, Isogai A (2012) Cellulose nanofibrils prepared from softwood cellulose by $\mathrm{TEMPO} / \mathrm{NaClO} / \mathrm{NaClO}_{2}$ systems in water at pH 4.8 or 6.8 . International Journal of Biological Macromolecules 51:228-234. https://doi.org/10.1016/j.ijbiomac.2012.05.016

Wang CY, Wu ZH (2002) The synthesis of the low-molecular-weight polyacrylamide by precipitation polymerization. Journal-Fujian Teachers University Natural Science Edition 18:61-63. http://dx.chinadoi.cn/10.3969/j.issn.1000-5277.2002.04.014

Yang, D., Stimpson, T. C., Soucy, J., Esser, A., \& Pelton, R. H. (2019). Increasing wet adhesion between cellulose surfaces with polyvinylamine. Cellulose, 26(1), 341-353. https://doi.org/10.1007/s10570-0182165-9

Yu Y, Wang Q, Yuan J, Fan X, Wang P, Cui L (2016) Hydrophobic modification of cotton fabric with octadecylamine via laccase/TEMPO mediated grafting. Carbohydrate polymers 137:549-555. https://doi.org/10.1016/j.carbpol.2015.11.026

Yui Y, Tanaka C, Isogai A (2013) Functionalization of cotton fabrics by TEMPO-mediated oxidation. SEN-I GAKKAISHI 69:222-228. https://doi.org/10.2115/fiber.69.222

Zhao M, Li J, Mano E, Song Z, Tschaen DM, Grabowski EJ, Reider PJ (1999) Oxidation of primary alcohols to carboxylic acids with sodium chlorite catalyzed by TEMPO and bleach. The Journal of Organic Chemistry 64:2564-2566. https://doi.org/10.1021/jo982143y

\section{Figures}




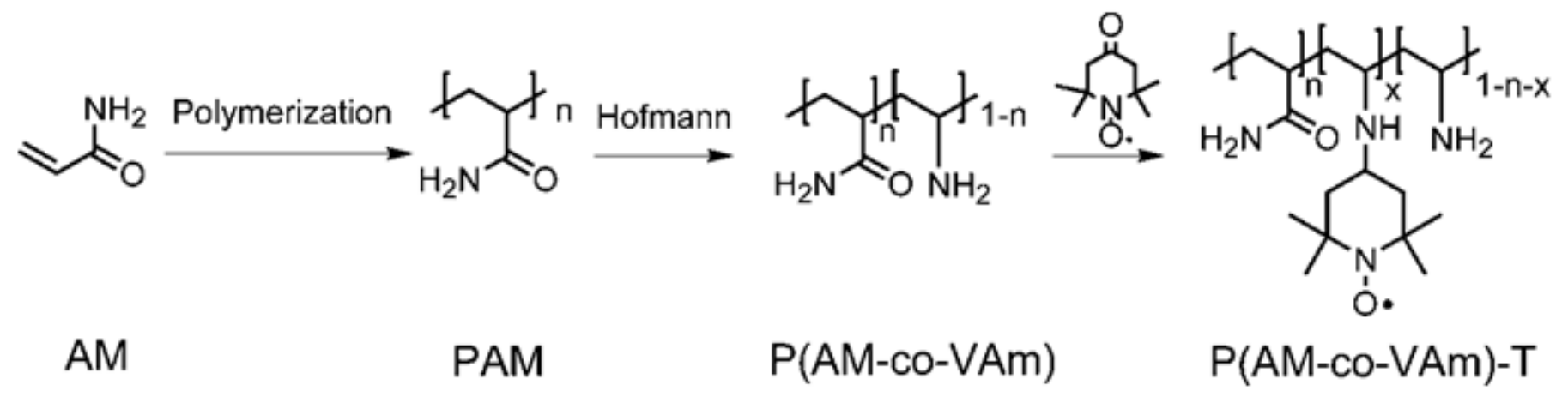

Figure 1

Synthetic route of $\mathrm{P}(\mathrm{AM}-\mathrm{co}-\mathrm{VAm}-\mathrm{T})$

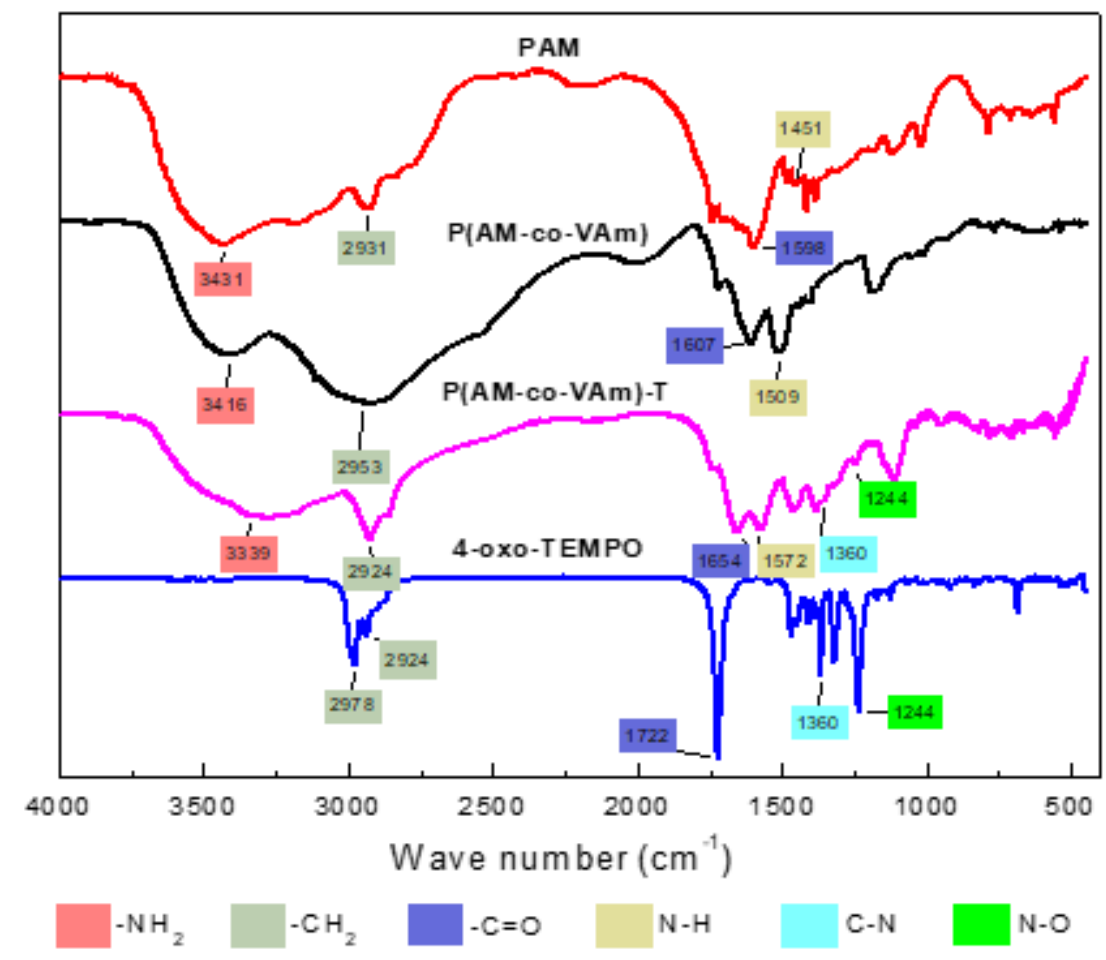

Figure 2

FT-IR spectra of PAM, P(AM-co-VAm), 4-oxo-TEMPO and P(AM-co-VAm)-T 


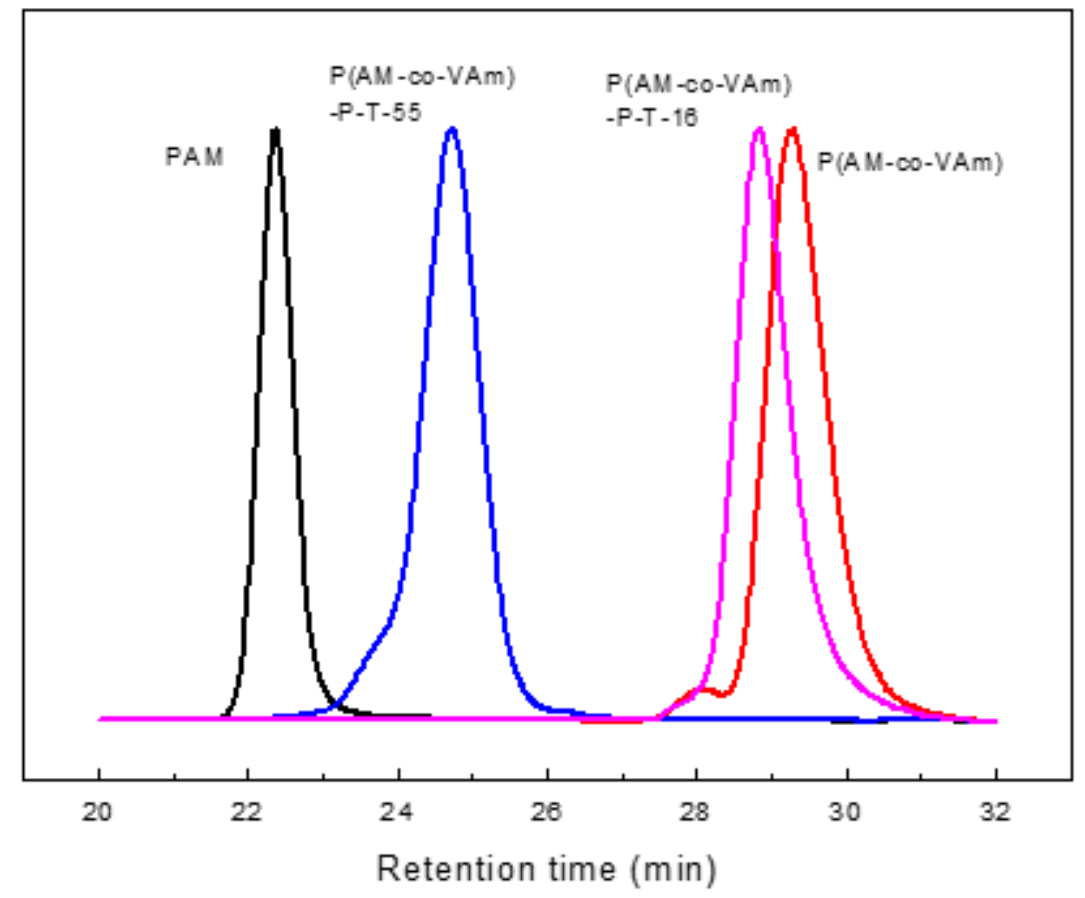

Figure 3

GPC curves of PAM, P(AM-co-VAm) and P(AM-co-VAm)-T

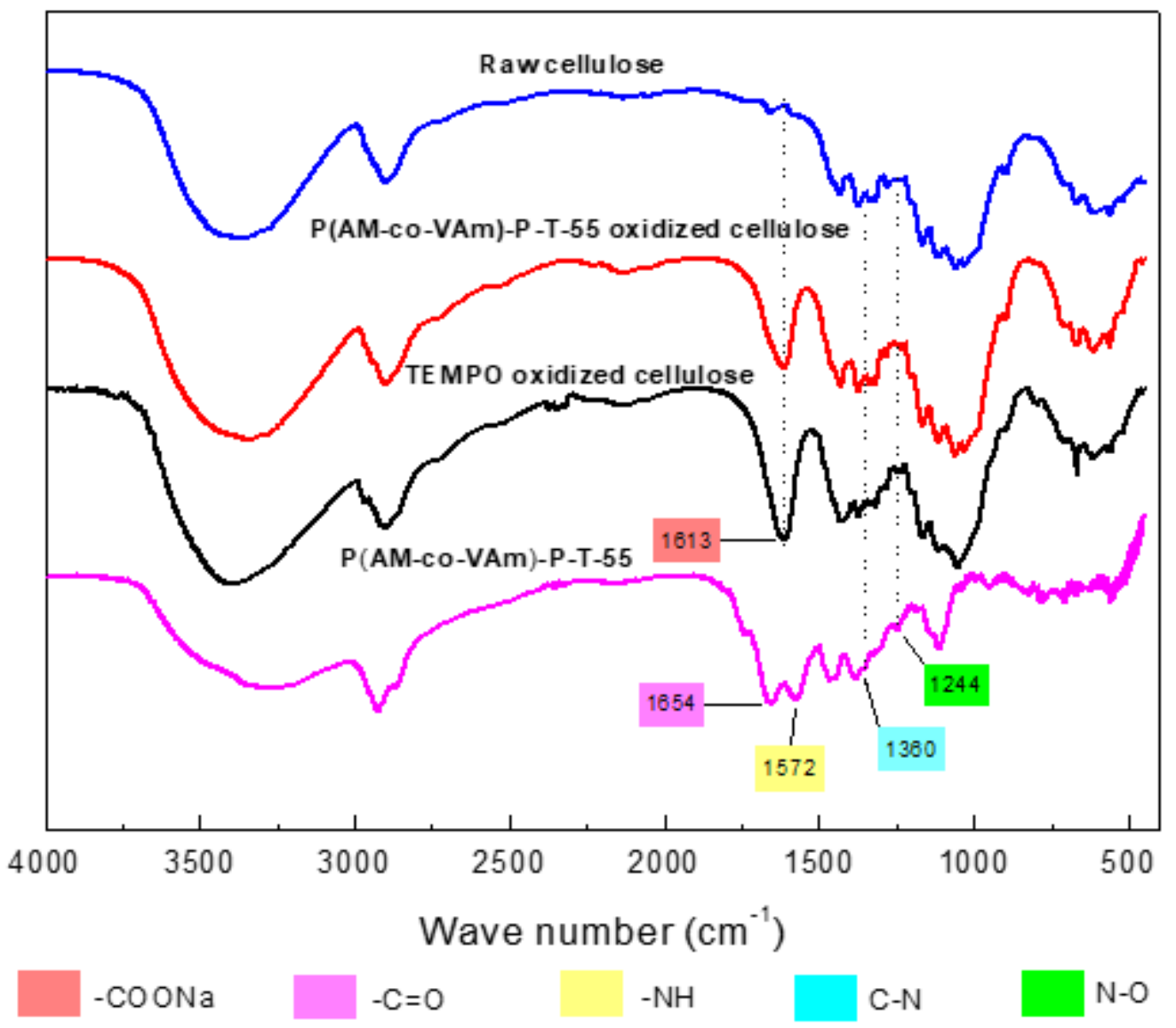


Figure 4

The FT-IR spectra of cellulose, P(AM-co-VAm)-T, TEMPO oxidized cellulose and P(AM-co-VAm)-T oxidized cellulose

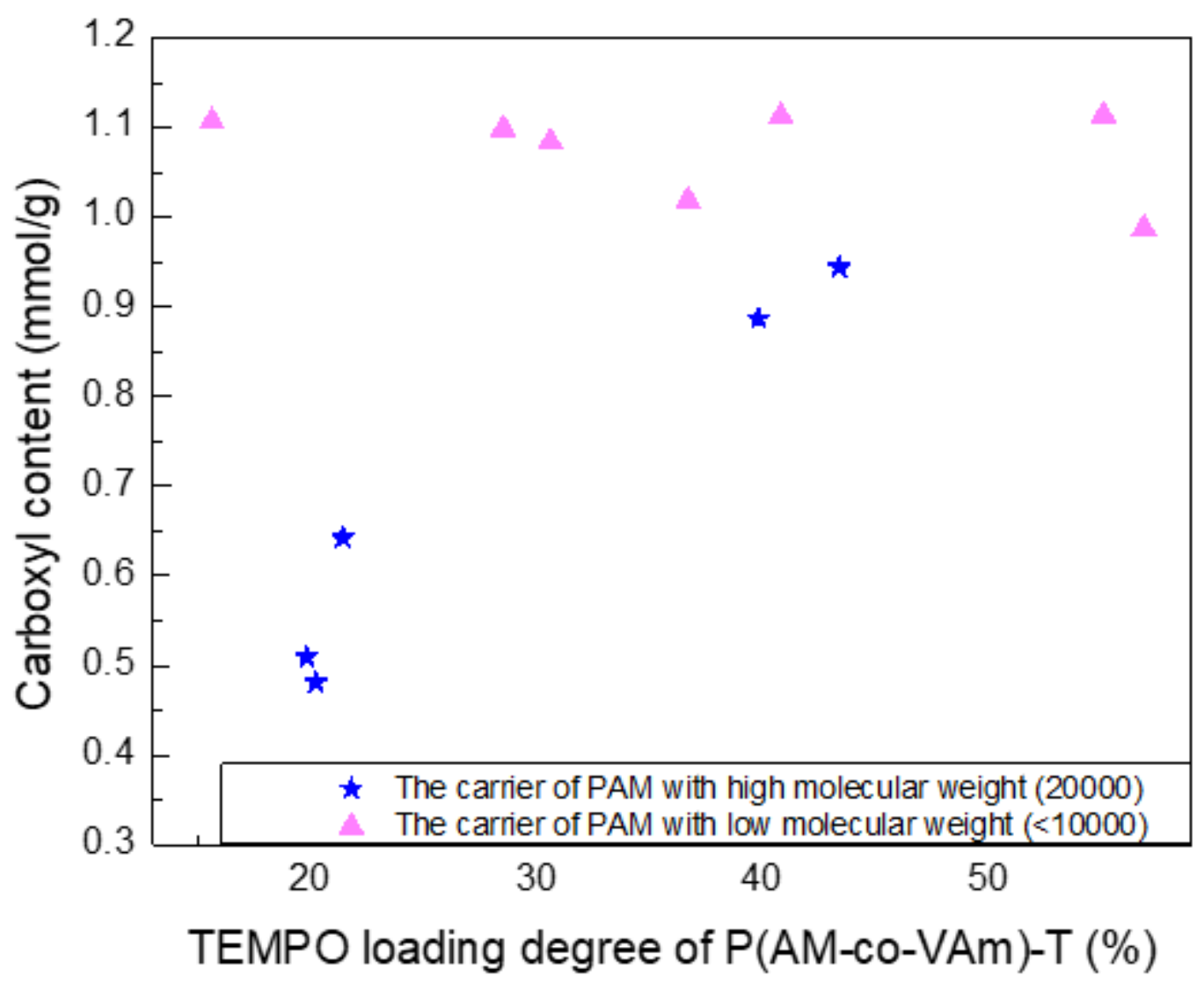

\section{Figure 5}

Effects of TEMPO loading degree of P(AM-co-VAm)-T on carboxyl content of oxidized cellulose

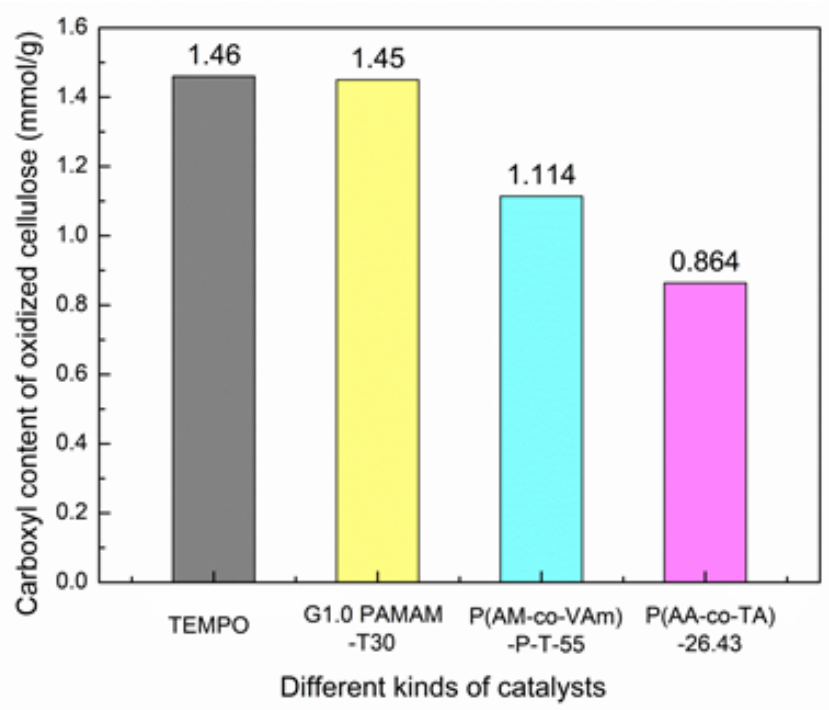

(a)

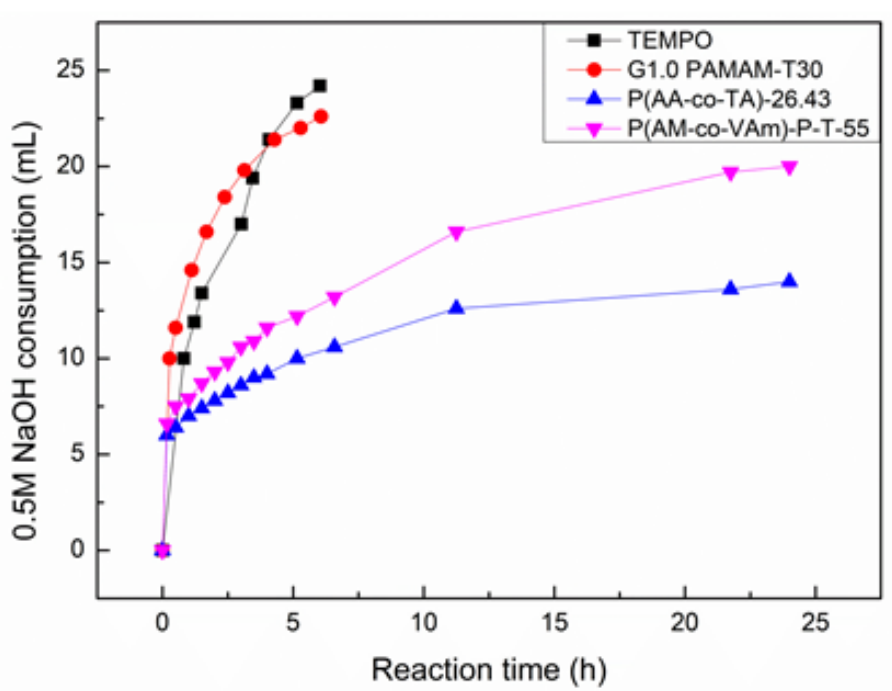

(b) 
Figure 6

Carboxyl contents of oxidized cellulose (a) and $\mathrm{NaOH}$ consumption amounts (b) for macromolecular TEMPO catalysts and free TEMPO
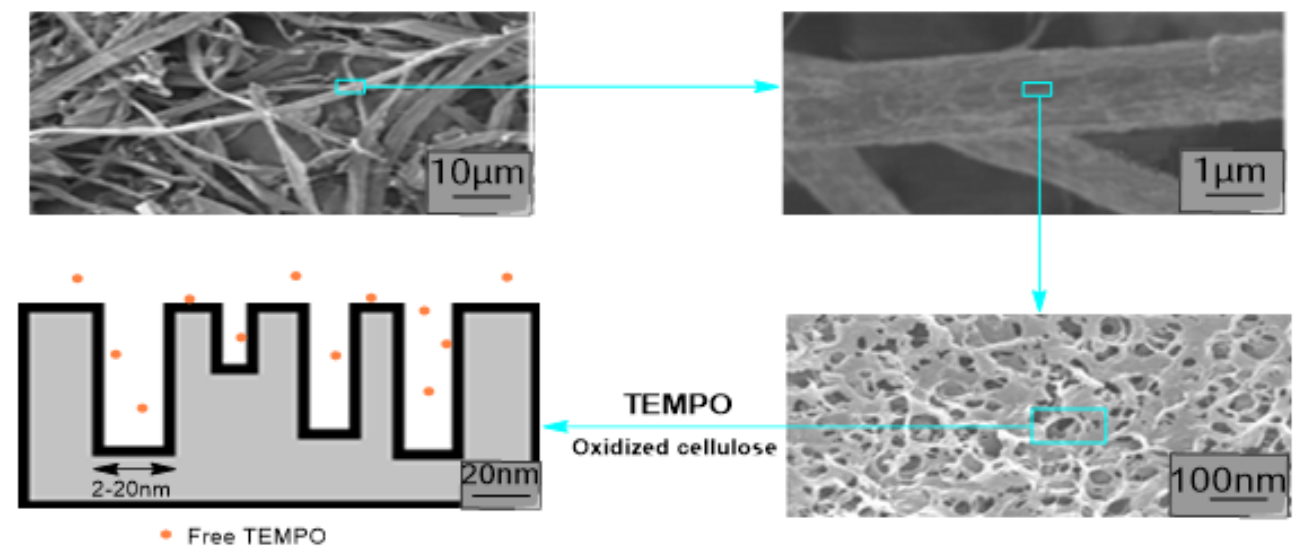

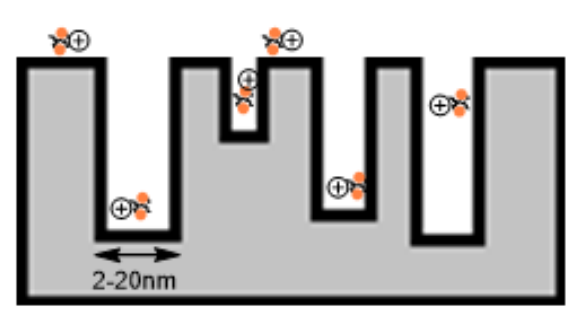

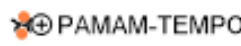

C PAMAM-TEMPo surface

II

C PAMAM-tempo in cellulose pores

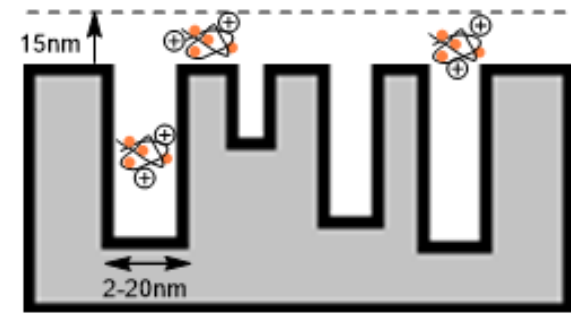

$\overbrace{\oplus}^{\oplus} \mathrm{P}(\mathrm{AM}-\mathrm{Co}-\mathrm{VAm})-\mathrm{T}$

$C_{P(A M-c o-V A M)}-T$ surface $\mathrm{V}$

$\mathrm{C}_{\mathrm{P}(\mathrm{AM}-\mathrm{OO}-\mathrm{VAM})-\mathrm{T} \text { in cellulose pores }}$

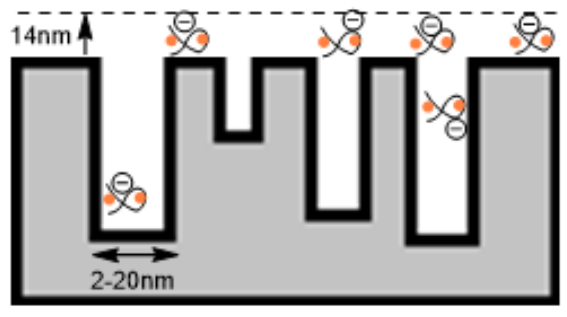

$D \oplus P($ AA-CO-TA)

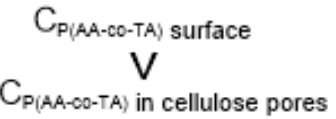

\section{Figure 7}

The distribution of TEMPO, P(AM-co-VAm)-T, PAMAM-TEMPO and P(AA-co-TA) on nanopores of cellulose during oxidation process 


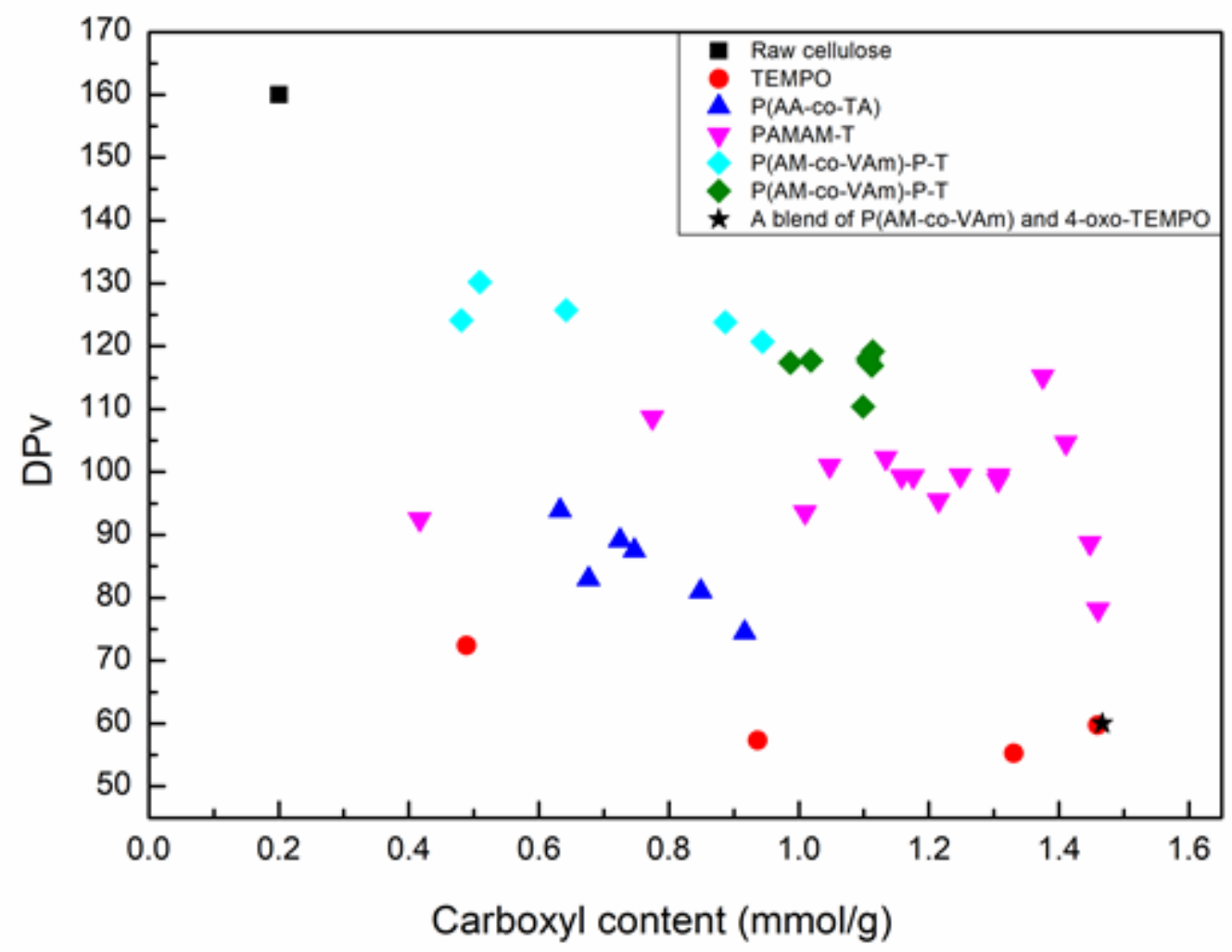

Figure 8

Relationships between DPv values and carboxyl contents for oxidized cellulose samples obtained with different catalysts 


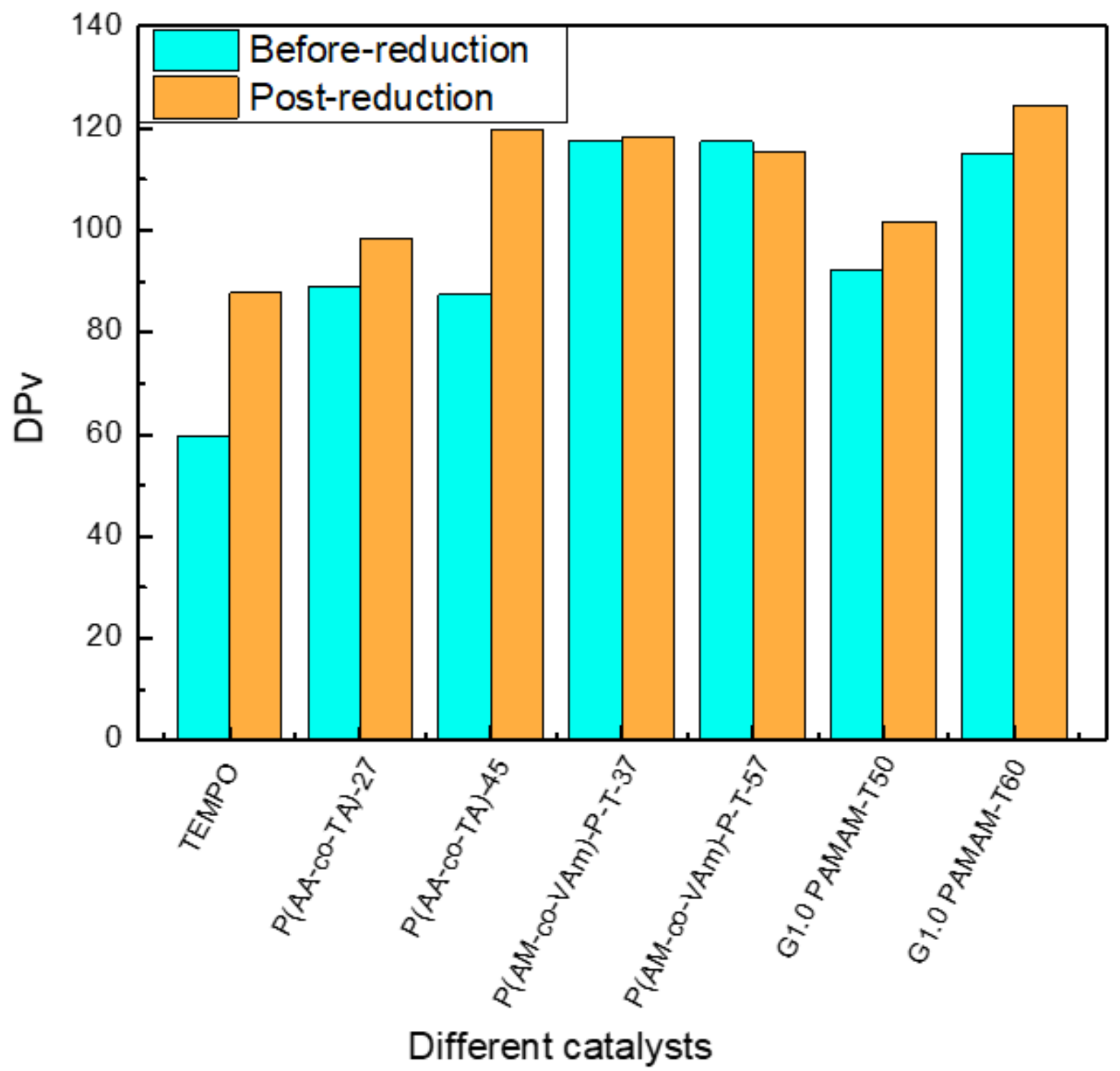

Figure 9

The DPv results of oxidized cellulose before and post reduction by NaHB4 for different catalysts 


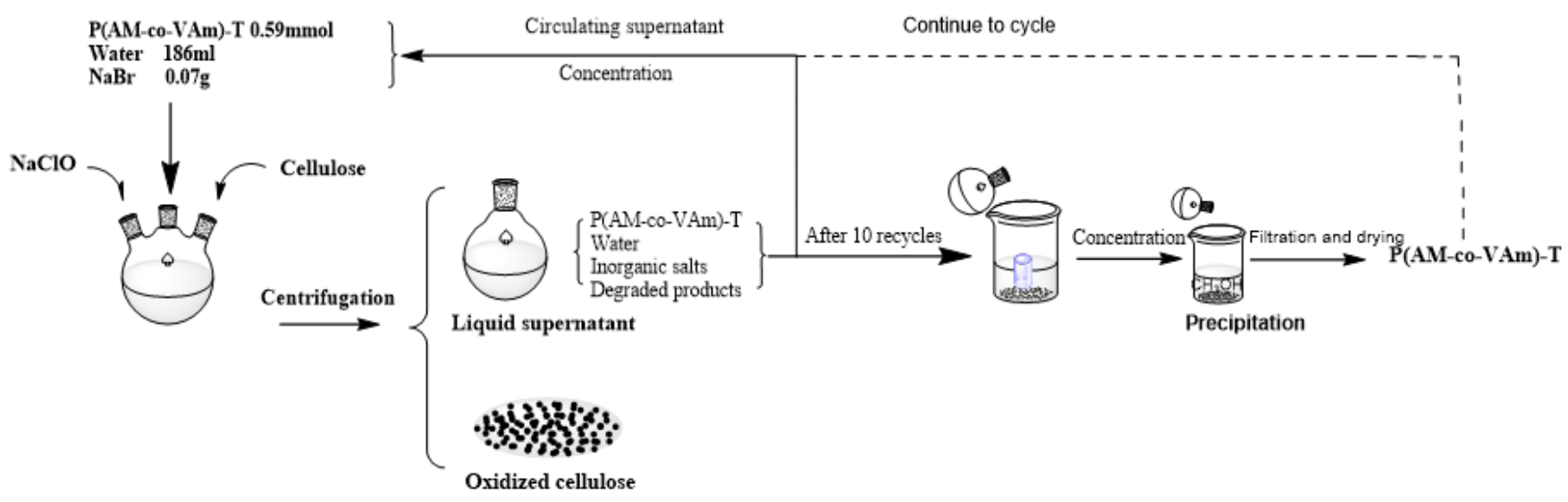

Figure 10

The recycling process of $\mathrm{P}(\mathrm{AM}-\mathrm{co}-\mathrm{VAm})-\mathrm{T}$

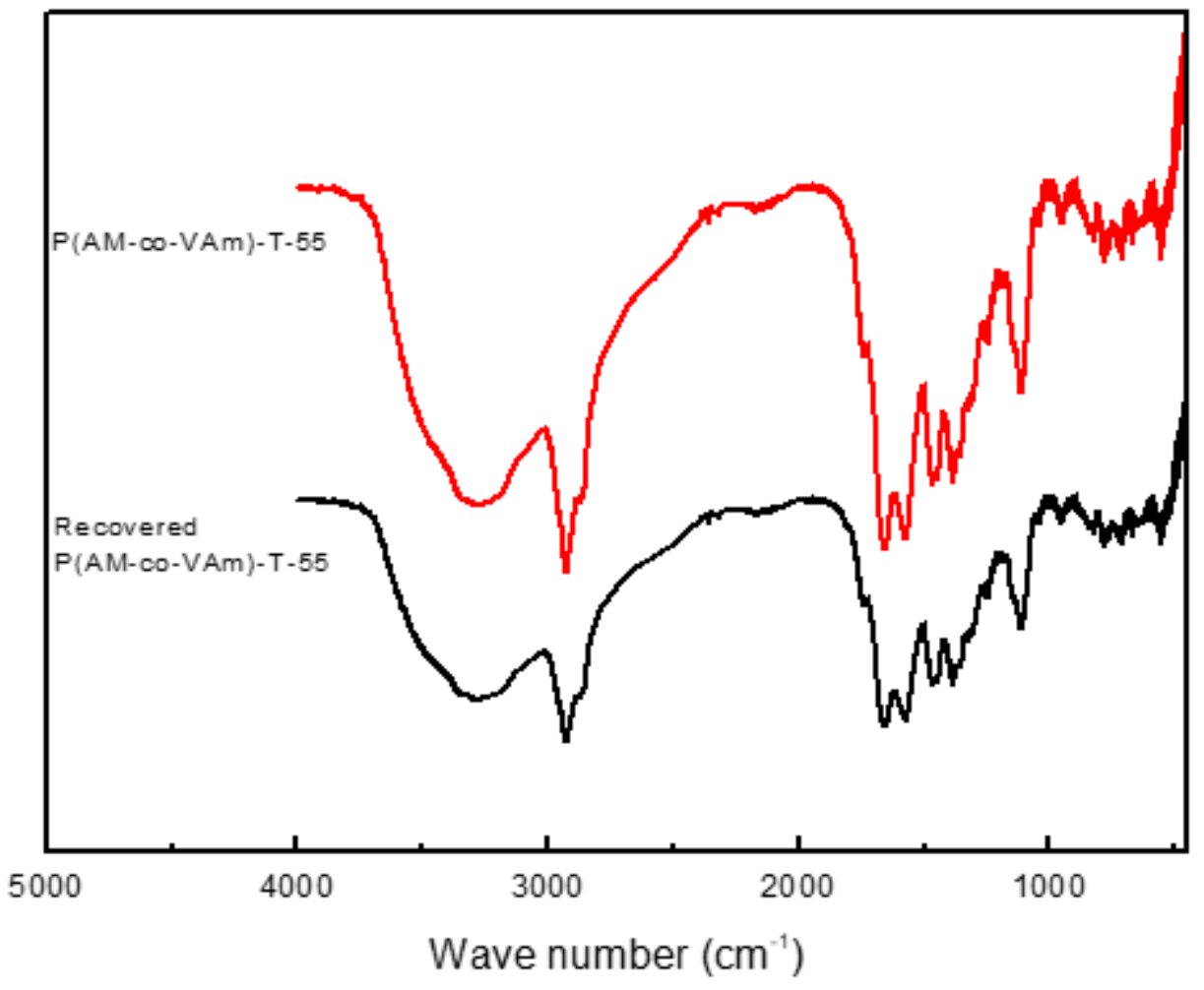

Figure 11

FT-IR spectra of P(AM-co-VAm)-T-55 before and after recovery 


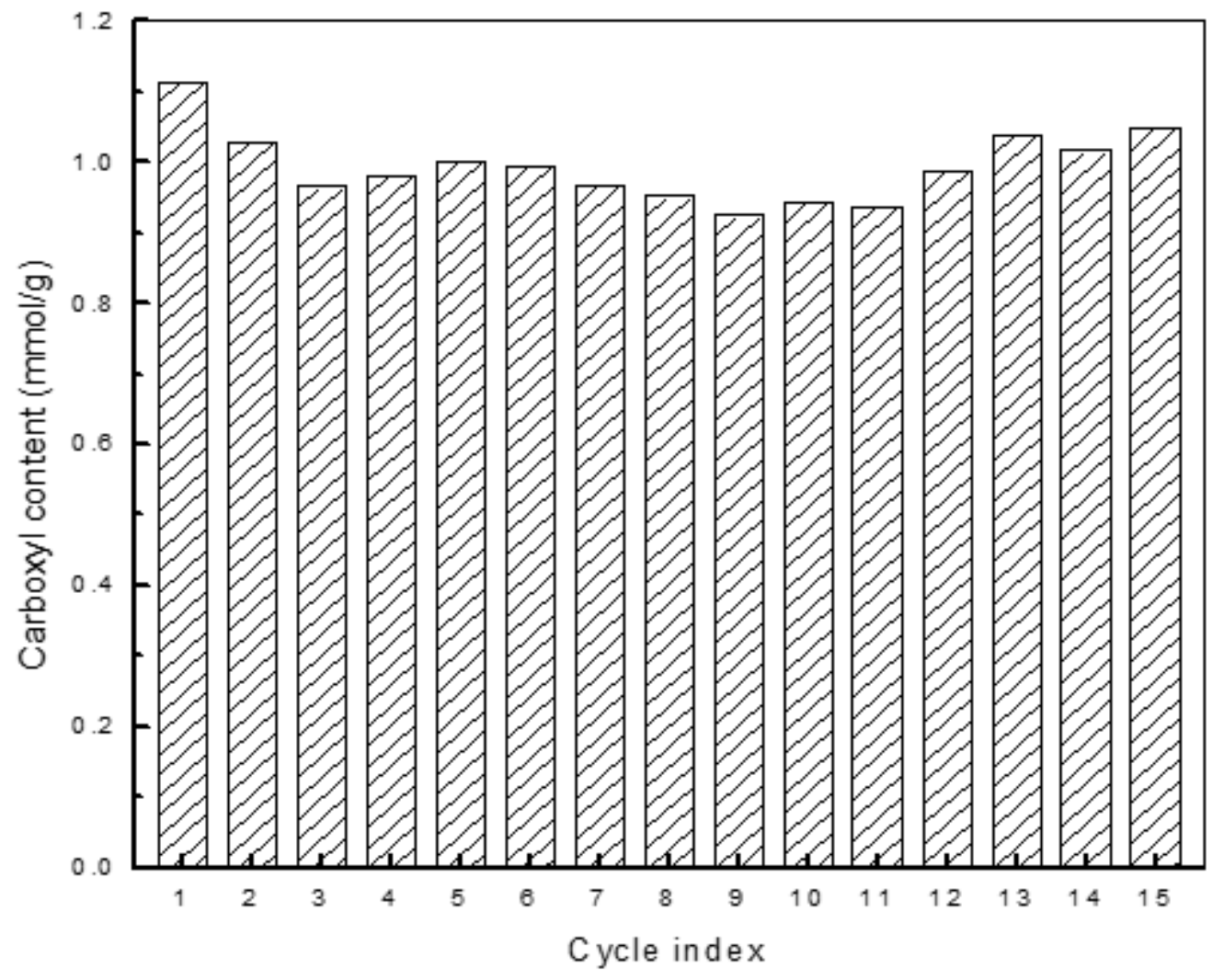

Figure 12

The recyclability of P(AM-co-VAm)-P-T-57 for cellulose oxidation 